\title{
Research on Synergistic Governance of Famous Historical and Cultural Villages
}

\author{
$\mathrm{Ke} \mathrm{Lu}$ \\ Wuhan University of Science and Technology \\ Wuhan, China 430070
}

\author{
Yimeng Chen \\ Wuhan University of Science and Technology \\ Wuhan, China 430070
}

\author{
Zhonghao Qu \\ Wuhan University of Science and Technology \\ Wuhan, China 430070
}

\begin{abstract}
Famous historical and cultural village is the important real carrier of traditional Chinese clan culture. It has a large number of material cultural heritages that cannot be copied, and its architectural style, characteristic and layout vividly embody the clan conceptand cultural view of traditional cluster villages in China. It also has intangible cultural heritages to be inherited, and many traditional customs are relatively completely preserved in ancient villages and towns. But what is easily neglected in the protection and development of ancient villages is the importance of cooperative governance among the main bodies of interest. There are many problems in the operation of ancient villages, which is the result of low level of cooperative development and the lack of effective liability and responsibility sharing mechanism. Therefore, in the context of cooperative governance, the protection and development of historical and cultural villages is explored, with the hope to provide the reference for the further development of famous historical and cultural village.
\end{abstract}

Keywords-famous historical; cultural village; cooperative governance; protection and development

\section{INTRODUCTION}

Synergistic governance is a governance concept that is derived from the idea of governance. "Synergistic" comes from the Greek word, meaning common and collaborative, and is a value philosophy. The current theory of synergistic governance stems from the collaborative learning created by the German physicist, Haken. The core of synergetics theory is self-organization theory (the study of the production and regulation of self-organization, etc.). This self-organization is carried on in accordance with synergistic function. Synergistic function is the basic concept of collaborative learning and synergistic theory, and in fact, it is the process of the organic integration and mutual interaction of various elements within the system and various subsystems. In the process, it emphasizes the difference and synergy between the system's internal elements (or subsystems), and stresses that dialectical unity of differences and synergy must achieve the overall effect, etc. Synergetics as a as the new theory to research common essential characteristics in completely different subjects breaks through the limitations of the previous linear science on organization and explores how to use the synergy between internal subsystem, competition and self-organization on the mutation point to form the mechanism thought of the structure. This synergy thought and theory obtains the development and reflection in modern management; especially in the government management field, with the rapid development of public affairs, the idea of synergistic governance is playing an increasingly important role in the field of public administration, as an important development direction of the government management field in the future.

In recent years, scholars have defined the connotation of synergistic governance theory, and tend to define synergistic governance as an open and coordinative overall system formed by many main bodies of right in public life, and through mutual coordination and function, it realizes the integration and appreciation of the power, thus efficiently conducting the management of public affairs, and ultimately achieving the goal of public interests. In short, synergistic governance theory is the development of governance theory; in the meantime of emphasizing the diversification of the governance body, complexity of governance system and interaction of governance process, it is committed to exploring synergistic governance can achieve the production of social cohesion, centripetal force, cohesion, and finally realize the win-win of cooperative parties.

To sum up, government's synergistic governance can be defined as: the sum of governance mechanism and governance way to work together, commonly manage public affairs within the scope in order to protect and promote the public interest, government departments and society, enterprises, citizens and the diverse legal governance bodies use the collaborative rules. This concept has four aspects:

The homing of government role means the government is no longer the only subject, and various social organizations including private enterprises, the third departments or individual citizens can become the legal subject of synergistic governance.

The relationship among the governance subjects is voluntary, equal and synergistic. Through synergistic 
governance, it can achieve the maximization of the efficiency of public affairs. The society takes synergistic governance model, making various elements organically combined together by effective ways and means, and its overall function is greater than the individual subsystems, and the sum of the function when they are apart, namely the overall function is greater than the sum of its parts' function.

Diversity of synergistic governance authority, synergistic governance needs authority, but the authority is not necessarily government agencies, and other social governance organs can exert and reflect their authority in public governance activities.

\section{PROBLEMS EXISTING IN THE DEVELOPMENT AND PROTECTION OF FAMOUS HISTORICAL AND CULTURAL VILLAGES AND TOWNS}

Currently, in the process of high-speed urbanization and urban expansion in China, historical villages which are $\mathrm{s}$ located in the edge of the city or the suburbs are gradually surrounded by city, turning into a part of the city. The demand of urban development for the rapid growth of land and the historical situation of villages in the development make historical villages rich in village structure, village imagery and village landscape and even historic buildings damaged. At present, the protection and development of the historic and cultural villages are being made all over the country. However, there are still many problems in the synergistic development of historical and cultural villages.

\section{A. Not High Synergistic Development Level}

Throughout the protection and development of current famous historical and cultural villages and towns, excessive administrative dependence tendency is still relatively common, the protection and development of famous historical and cultural village (town) seems to lack sufficient autonomy, and synergistic development level remains to be improved.Currently, there are three aspects of the lag in synergistic development for the protection and development of the famous local historical and cultural villages.

Firstly, government intervention is excessive. Excessive government hosting and excessive government intervention are reflected by "nanny" hosting of a vibrant historical and cultural unit project with good development potential, and the government take sadministrative management, the protection of cultural relics, and is solely responsible for the protected area, "as both father and mother", as well as force to take administrative measures to intervene and affect the protection, development and management of the ancient city and ancient village. This is different from the "museum" protection, and the consciously closed protection way that is not be suitable to the development of ancient villages and towns manifests the local government has worry about the market-based management of the ancient village project, and is not confident in the market-based operation.

Secondly, protection and development is stalled. The sharing tax system in China restricts the use of local government funds for long time. The local government has more powers but lacks funds, and its special funds for the cultural heritage protection is generally more limited, especially the special funds that is dedicated to the protection of historical villages. For a long time, the government is in a state of "debt" in the construction of historical villages, and many traditional historical villages lack reasonable protection and restoration for shortage of funds. Some governments of famous historical and cultural villages do not put enough money into the development and protection, but adopt the method of killing the goose that lays the golden eggs to increase income taxes and other miscellaneous expenses, which restricts the sustainable development of historical and cultural village. Since the local government's financial resources are limited, and lacks focus, it causes this ancient villages to be protected or renovated have not be protected and reformed in a timely manner, ancient villages face falling to decline, most local residents leave the hometown to go out to make a living due to pressure from life, and some ancient villages and towns even face the danger of disappearing overnight.

Thirdly, commercial development is excessive. Government or regulatory department does not implement the function of supervision and monitoring in a good way. The development of tourism in the ancient villages bring considerable economic benefits for the local government, and at the same time, regulatory department has neglected the effective protection of famous historical and cultural village and town, making the the ancient town's history and culture gradually lose and become an empty shell. Now Lijiang old town belongs to the latter, and in 2010, the backpackers of the ancient city of Lijiang generally felt that Lijiang, now, has only feasting and party every night, and honest folkway has ceased to exist.

\section{B. Evident Homogenization}

Historic and cultural village and town have diverse values of culture and natural heritage, and are the villages with different characteristics that are formed by different nationalities in different natural humanities environments. Every traditional village is the unity of traditional culture and space layout art of the village, and the precious heritage of carrying cultural memory on the basis of natural environment. These famous historical and cultural villages and towns are often rooted in the profound long outstanding traditional culture, with some important historical figures and events, and are the "living fossil" and "museum" of Chinese national spirit as well as historical and cultural heritage, with great historical value. These famous historical villages and towns with unique nature and humanities have economic value for the development of tourism, but in the construction of rural urbanization, the traditional villages, especially the famous historical and cultural villages with commercial exploitation value are constantly under "constructive, developmental, tourist" damage, in which "characteristic crisis" of "thousands of villages being the same" makes famous historical and cultural villages more and more convergent, reducing its unique historical and cultural value.

\section{Lack of Effective Planning as well as Protection and Supervision System}

Due to the lack of effective planning of long-term development strategies and lack of constructive institutional 
guarantee, villages in China, especially traditional villages, are gradually decreasing. Relevant survey data show that China had 3.63 million natural villages in 2000 , and by the end of 2010, it had fallen to 2.71 million. The survey figure of traditional villages in China in 2012 show that the number of existing villages in China had decreased to 2.3 million, and the rapid momentum of the village disappearing was unstoppable. According to the statistics, at present, 31 provinces have registered and reported 111,567 villages with traditional properties, including 646 of the first batch of traditional Chinese villages. Currently, there are many examples of the lack of scientific planning in ancient villages and blind construction, such as the construction of phoenix new town. According to statistics, phoenix town received a total of 6.0014 million person-times of tourists in 2011,realizing 1.431 billion yuan's income of the ancient city tourism. The tourism resources of the ancient city brought considerable economic benefits to the local. However, due to the lack of long-term planning science, significant economic benefits did not make the ancient city of phoenix realize the environment optimization, but to make environmental pollution increasingly serious.

In addition, relevant laws and regulations on the protection and development of ancient villages and towns are not well established, and the government's protection is not sufficient. At present, China has introduced "Act of the Preservation of Cultural Relics Promulgated by P.R.C.", but there is no special law for the ancient villages and towns as material and cultural heritage and intangible cultural heritage. Also, the surrounding environment, water, etc. of ancient villages and towns are in lack of definite legal provisions. Some local governments lack understanding, and are unaware of precious historical and cultural value of the ancient villages and towns, but blindly pursue the rapid economic growth. Without the relevant departments' reasonable planning, new area near the ancient villages and towns is randomly constructed, with serious damage to the original style of the ancient villages and towns. Some local governments advocate the protection of ancient villages, they just chant empty slogans and do not implement the protection of the ancient village, so as to miss the precious protection opportunity. In particular, precious cultural relics, which are some most effective material carriers of ancient villages, have not been repaired in time. Some historic sites that have been renovated have been unused for a long time.

\section{Lack of Effective Sharing Mechanism of Rights and Responsibilities}

The sharing mechanism of rights and responsibilities can effectively guarantee the orderly operation of ancient village and town. Not only the government should clarify the administrative rights and responsibilities, but also the developers (enterprises and merchants) shall enhance the social sense of responsibility in addition to economic benefits, and make profit into returns, used for the subsequent development of ancient villages and towns. As residents living in the ancient villages and towns, in addition that personal interests are protected and satisfied, it should start from the overall interests of protection and development, and make appropriate concession. The government, the enterprises and the villagers share interests, share responsibilities and share rights with each other, which is the fundamental of the healthy development of the ancient village.

As a local government, due to speeding up the urbanization process, taking only GDP in the first place, the one-sided pursuit of economic value of famous historical and cultural village, and focusing on development but neglecting protection, it causes a lot of construction in various places, and the inundation of image engineering and prestige projects, so historical and cultural ancient villages and towns with potential value are hard to survive in in this wave of engineering. The government often starts from the interests of city, district, or the whole area, and only will take the protection and development of ancient villages and towns as one of the links, which certainly will cause that the protection and development of ancient village cannot completely meet the demand of the ancient villages and towns.

As enterprises and merchants, they aim to maximize profits. Relatively, they inadequately invest in social responsibility and returns. When problems arise in the operation of the ancient village, enterprises and merchants often throw problems and responsibilities to the government, blaming its administrative deficiencies. As mentioned above, after phoenix culture tourism company got profits, it did not invest more money and energy in late development and planning of the ancient town, but depends on the policies of the government and the administrative intervention to solve a series of problems brought by the traffic overload in the scenic spot. This often gets half the result with twice the effort, and then things go contrary to one's wishes.

As villagers, on the one hand, the urbanization process makes the social basic-level contradictions more and more prominent, and their living demands are not satisfied. Main reason is lack of effective communication mechanism between the local residents and the government. The grassroots' appeal is difficult to be conveyed to the relevant government departments and the ancient villages and towns development department is unable to fully estimate all the various needs of the masses in the process of advancing reform, causing the contradiction between the grassroots and the local government is increasingly intensified. On the other hand, the local residents have a weak sense of protection, and the construction of new rural villages has accelerated the disappearance of ancient villages. Because most local residents have no comprehensive recognition of the value, prospect, etc. of the ancient villages and towns, and just see the short-term interest, they are not willing to spend money on repairing the ancient dwellings where their generations live. In ancient villages whose infrastructure lags behind, many valuable ancient homes face natural destruction and sales by human.

\section{STRATEGIES FOR THE SYNERGISTIC GOVERNANCE, PROTECTION AND DEVELOPMENT OF FAMOUS HISTORICAL AND CULTURAL VILLAGE}

The protection and development of the historic and cultural village requires multilateral cooperation and 
governance, which means that the government department and the society, enterprises, citizens and the diverse legal governance bodies use the synergistic rules, governance mechanism and governance way to work and manage together within the scope. In this model, the government is no longer the only subject of governance, and various social organizations including private enterprises, the third department or individual citizens can become legal main body of synergistic governance. Their relation is voluntary, equal and synergistic. The synergistic governance mode make various elements organically combined together by effective ways and means, and the overall function is greater than the sum of the individual subsystems, namely the whole function is greater than the sum of its parts' function, to better protect and develop historical and cultural village.

\section{A. Socialization Synergy}

The concept of "socialization" has been applied in many fields. The socialization of developing and protecting the ancient villages and towns is the development and protection of ancient village (town) protection attended by local residents, who comply with the major policies of the nation, and become "contributor" of the development and protection of ancient village (town). In terms of historical and cultural protection and development,socialization requires changing the management model that the government is in charge of all things, and the future development of the ancient village (town) shall be borne by enterprises and local residents. Through the establishment of the socialization history and culture protection system, the national protection for the historical sites is changed into social protection, finally realizing the public participation, to meet the need of synergistic governance under the background of urbanization. The establishment of a historical and cultural protection system other than government organization, and the realization of the social management of ancient village (town) are also the ideal target for the protection of historical and cultural heritage.

The specific requirements of socialization management include: [1] the historical and cultural protection and development is not only managed by government office and government, but also follows the overall policy, synergistic management, fully mobilizing the enthusiasm of all sectors. The government administration is transited to the shared responsibility by government, enterprises and residents. The government does not interfere with the investment of enterprises, but create an environment in which the whole people participate in the development and protection of the ancient village by formulating relevant policies and regulations. [2] The fund management of the development and protection of ancient village (town) is strengthened. According to both social and economic development condition, it should timely increase capital investment, and strengthen the management of economic returns brought by ancient village (town) to the society, so as to improve the rational use of funds.

\section{B. Target Synergy}

Due to being restricted by tenure system, local government officials easily ignore the long-term goal in order to quickly make achievements, and then blindly carry on projects to establish important points. These engineering and projects that seem to drive a duck onto a perch mostly difficultly fit the requirements of long-term goal planning, and even the project itself would be easy to die early, even becoming nondescript project. So, the government should follow the principle of protection before development, and carry on protection and development of "restoring the old as the old" for the ancient village (town), making the ancient village shown with its original ancient style and appearance to the world. However, on positioning and direction for the future development planning of the ancient village (town), the governments at all levels of government still need to strengthen the planning guide, and clarify regional function division for the development of ancient village (town). Thus, when choosing the development and management subject, the government should not only consider scale, experience and strength of assigned enterprise, but also give enterprises full confidence in development and operation. In the process of implementation, according to the common goal of three parties, it should strengthen the cooperation of all aspects, and in addition to urging enterprises to increase investment and promote the project, reasonable and lawful revenue profit of the enterprise also should be fully considered, strengthening cooperation to eliminate enterprise's mechanism and system obstacle in the development of the project and to promote the further development of the ancient village (town). At the same time, the government also should fully respect the wishes of rural residents, fully respect the suggestions of them as the "host" of ancient village (town). This is the respect for the survival and life of people in history, and the respect of survival and life of modern people. In the process of planning and construction, it should fully solicit the opinions of the village community and the villagers, and for part of the planning and construction that most of the villagers are against, the adjustment is made in accordance with the law; fully relying on two levels of district and street, a good job of propaganda and explanation to the villagers should be conducted, to ensure the project smoothly operates.

\section{System Synergy}

Complete and good mechanism is the guarantee for the healthy operation of ancient village (town) project. The development and operation of enterprises needs the constraints of the laws, rules and regulations, and also needs supporting policies and institutional support. The government's administrative behavior also must be in the corresponding laws, regulations, and the system framework, to maintain the continuity and stability of the project development, reduce the subjectivity and randomness in administration, and set up the government's credibility. The development of ancient village should the basic principle that"government sets platform, enterprise acts, and villagers (tourists) benefit", forming a series of corresponding laws and regulations, system and working mechanism, to ensure that all parties can adapt to each other, and the protection and development of the ancient village (town) can reasonably carry on, therefore, relevant system to promote the synergistic development should be established, such as setting the legal system for the protection of environment 
and cultural relics, formulating community residents to participate in the system, and supervising synergistic development, and improving the level of social organization's synergistic management, etc.

Firstly, relevant laws and regulations should be formulated and improved, and development, protection policies and policies to attract investment should be improved. For example, "regulations on the protection of ancient villages" is formulated. The protection of the ancient village (town) shall be incorporated in the track of legal system; with reference to"protection ordinance on historical and cultural city, town and village", related regulations and rules on protection of historic and cultural village are formulated, to make the protection of famous city in accordance with the law and regulation. [4] The "constructive" damage should be prevented from the continuing spread among historic cultural towns. [5]

Secondly, the rules of land control should be well grasped to make room for further development. The land for the village development should be implemented. In addition to the implementation of immigration area of local residents, the planning and construction department shall make overall planning, effective integration for commercial service supporting area within the above area, carry out a complete set of land use for the corresponding catering, shopping, leisure, entertainment and hotel hostel, avoid repeating cluster of function areas or lack of a complete set of supporting facilities, and improve the land utilization.

Thirdly, smooth dialogue and coordination mechanism should be set. To straighten out the coordination work for the ancient village (town) protection and development, the government should set up a leading group of ancient village (town) protection and development. Through the leading group dialogue platform, the issues and differences in the ancient village (town) protection and development can be coordinated, negotiated, and solved.

Fourthly, the role of social forces can be played. Ancient village (town) may establish development research association. Under the promotion of the ancient village (town) research association, it makes the development of ancient village (town) have little detoursor not take wrong path. It must fully launch the role of social forces including seminar experts, listen to the experts' and scholars' appeal and the suggestion, timely absorb the scientific and reasonable suggestions and opinions, and transform them and apply them to the business development in the process of implementation.

Fifthly, "delegate power" should be learned. Within the scope of the laws and regulations, the government should learn to "delegate power" to reduce administrative intervention, put an end to chief executive's will, leadership's personal intention to interfere with the operation of the whole project, and give the project to the enterprise and the market. In order to reduce remuneration such as visit and guidance and reduce the reception pressure of enterprises, it should give the enterprises full autonomy and the space to develop independently.

\section{Interest Appeal and Synergy}

Government is the main body of public administration, not for profit, but for the effective promotion of public interest, providing welfare for people. Therefore, in the protection and development of ancient village (town), the interest appeal of government should be consistent with the public interest, which is mainly reflected as follows.

First, it is the demand made by cultural platform. As government, in the early development of ancient village (town), it will certainly invest a lot of financial capital, and make rescue and renovation for the buildings with the historical and cultural protection value to reshape the ancient village (town) to face the society. In the future, with the aid of the precipitation of an ancient village's (town) history and culture, it will further polish tourism brand of the ancient village (town), optimize the ancient village's cultural tourism resources, and become an important carrier and platform of strong cultural city and cultural area. Secondly, it is the appeal for the pursuit of regional economic development. According to the target, the ancient village (town) will be forged as a national scenic area, which will certainly inject new tourism economic power for the ancient village (town), promote the overall upgrade of the region's tourism industry supporting, and motivate the stable growth of GDP. It is worth mentioning that government should distinguish right, liability and interest in business development process, especially when the ancient village (town) project is on track and starts to generate considerable economic benefits and social benefits, the government must abide by the identity positioning of "platform establishment" strictly, be careful not to get caught in the wrong recognition of "competing with people" and "competing with companies".

As assigned enterprise, it certainly takes the pursuit of economic benefits in the first place, but as discussed above, the development and protection of historical and cultural village and town is bound to be a long-term project, which is not only difficult to get profit in the short term, but also needs to invest a lot money and effort to make the project on track.It imposes a high requirement for corporate social responsibility and requires assigned enterprises to engage in public affairs with positive and beneficial attitude. In the pursuit of economic interests, it should pay attention to play to the social benefit of enterprises, and social returns, and return the profit from the project to the village. Through establishing school, helping the poor, etc. it should be dedicated to social public welfare and public management affairs, and engage in the development of village construction, benefiting the people.

As the owner of ancient village (town), local residents are the most direct beneficiaries of the protection and development of ancient village (town) project. Project management can make the collective and individual income increase significantly, effectively replace the low-end industries, introduce high-end tourism service industry, enhance the overall quality of floating population, reduce the public security criminal ratings, and improve environmental health. In order to the long-term development of ancient village (town), the people of ancient village (town) should take a long-term perspective, and even reasonably make a 
compromise if necessary, so as to provide more space for the development of ancient village (town) project development. [6] Firstly, they can appropriately migrate to the periphery of the tourist center. As the project is deepened, the popularity of travel route will continue to improve, and the tourism's central area is not suitable for the villagers' daily life, so the villagers should move to the areas surrounding the central area through the government compensation step by step. Secondly, it is necessary to carry forward the excellent historical culture of ancient village. Everyone of ancient village (town) is the carrier of hundreds of years' history of ancient village (town); every villager's behavior and literacy manner represents the image of ancient village. The village society should cultivate the villagers' cultural awareness [7], actively excavate the ancient village's famous stories, and arouse the honor and responsibility of the villagers to love the village.

\section{CONCLUSION}

In a word, in the process of protecting and developing famous historical and cultural towns, only from the global perspective to seek the correct processing and development mechanism can it satisfy the requirement of urban development and construction, and create conditions for the development of famous historical and cultural town and village in China.Therefore,only under the guidance of synergistic governance theory and sharing mechanism of responsibility and right, it aims to establish the new mechanism to protect "government leading,enterprise support,social participation", and integrate its protection and development into scientific, standardized and legalized track, so that the traditional style of China's famous historical and cultural village and town can be kept.

\section{REFERENCES}

[1] [UK] Ebenezer Howard, translated by Jin Jingyuan. Garden Cities of Tomorrow.Commercial Press, 2000 (12)

[2] Zhang Jie. Theory and Practice of New Urban Planning-century evolution of garden city idea. Beijing: China Architecture \& Building Press, 2005: $16-27$

[3] Edward Arian. The Unfulfilled Promise: Public Subsidy of the Arts in America [M].Philadelphia: Temple University Press, 1989

[4] Lin Chengbin. Famous historical and cultural village in China and its protection strategies.China Agricultural Museum, Beijing, 100125

[5] Chou Baoxing. Protection and utilization strategy of famous historical and cultural town (village) in China. Urban and rural construction, 2004(1)

[6] Zhang Xiaodong. Utilization and management of cultural protection in the development of Ancient Whampoa Anchorage. Cultural relics management center, Zhughai, Guangzhou.

[7] Nie Cunhu. Research on strategy and action of the protection of ancient villages---a case of Xiazhou village in Shanxi. Minzu University of China, 2011

[8] Jon Pierre, Chen Wen, Yingying city. The history of political theory, theory of city governance and comparative political theory of dynamic foreign city [J]., 2015, (12): 59-70. 